\title{
Gastrointestinal Manifestations in Patients with Chronic Kidney Disease
}

\author{
Shivraj', Venugopal.K ${ }^{2}$ \\ ${ }^{1}$ Assistant Professor, Department of general Medicine, Navodaya Medical college and research centre, Raichur, ${ }^{2}$ Assistant Professor, Department of \\ general Medicine, Hassan institute of medical sciences, Hassan.
}

\section{Abstract}

Background: Chronic kidney disease is a silent epidemic of the 21 century. Surveys have suggestedthat as many as $16 \%$ of the adult population have CKD1. The most common, non -renal, chronic disorders in patients with ESRD are gastro intestinal disorders2. Among upper gastrointestinal lesions caused by chronic kidney disease gastritis, an esophagus is,gastric ulcers are the most prevalent lesions. Here an attempt is being made to study the upper gastro intestinal changes in chronic kidney disease and evaluate theirrelationship with the stage of CKD or GFR. Objectives: 1. To determine the prevalence of various upper gastro intestinal lesions withthe use of fibro optic endoscopy.2. To evaluate the relation between the gastro intestinal lesion with the stage ofCKD or GFR. Subjects and Methods: We conducted a cross sectional study on 50 patients ,who are diagnosed to haveChronic kidney disease and being presented to OPD and admission in NavodayaMedical College and Research Center, Raichur over a period of one year. All patientswith chronic kidney disease underwent upper gastrointestinal endoscopy wereincluded in the study. Results: Majority of the subjects belongs to age group of 31 to 40 years (26\%) and least belongs to 70 to 80 years age group (6\%). Out of the 50 subjects, males were 28 and females were 22 .Majority of the cases in our study belonged to stage IV. $84 \%$ of the cases had upper gastrointestinal involvement on endoscopic examination in our study. Erosive gastritis (26\%), either antral or fundal, was the predominant lesion found on endoscopy. Majority of the subjects having erosive gastritis, had stage IV CKD (53.8\%).Out of 50 cases in our study $55 \%$ of subjects had lesions of the stomach, $26 \%$ of subjects had lesions in the duodenum, $19 \%$ of subjects had lesions in esophagus. Out of 50 subjects in our study $52 \%$ were undergoing haemodialysis and $48 \%$ of subjects were under conservative management. Majority of subjects undergoing haemodialysiswere belongs to stage V. Conclusion: Majority of the patients with chronic kidney disease have upper gastrointestinal involvement on endoscopic evaluation. Erosive gastritis is the most common upper gastrointestinal manifestation in our study. Upper gastrointestinal manifestations are predominant in stage V. Upper gastrointestinal findings are frequently observed in chronic kidney disease patients on dialysis. Early diagnosis and management can reduce mortality and morbidity and prevent fatal complication like massive upper gastrointestinal bleed.

Keywords: Chronic kidney disease, Upper gastrointestinal manifestations, Erosive gastritis.

Corresponding Author: Dr. Venugopal. K, Assistant Professor, Department of general Medicine, Hassan institute of medical sciences, Hassan.

Received: September 2019

Accepted: September 2019

\section{Introduction}

Chronic kidney disease is a silent epidemic of the 21 century. Surveys have showed that as many as $16 \%$ of the adult population have CKD. ${ }^{[1]}$ its occurrence is universal. Every year over one lakh people in India are diagnosed with CKD necessitating dialysis or kidney transplant. Patients with end stage renal disease often suffer from co morbidities like diabetes and cardiovascular disease. The most common, non -renal, chronic disorders in patients with ESRD are gastro intestinal disorders. ${ }^{[2]}$

Chronic kidney disease encompasses a spectrum of different patho physiological process associated with abnormal kidney function and a progressive decline in glomerular filtration rate. A recently updated classification, in which stages of chronic kidney disease are stratified by both estimated GFR and degree of albuminuria, in order to predict the progression of the disease. CKD is a clinical syndrome due to irreversible renal dysfunction leading to excretory, metabolic and synthetic failure culminating in to accumulation of nonprotein nitrogenous substances and present with various clinical manifestations.

ESRD is described as a terminal stage of CKD that without replacement therapy would result in death. Despite various etiology, CKD is the final common pathway of irreversible destruction of nephrons ultimately resulting in alteration of "Milieu interior" that affects every system in the body. One such system in the body is Gastro Intestinal System. Gastro Intestinal Symptoms are common in Chronic Kidney disease ${ }^{3}$ patients

Although the type of symptoms also vary considerably in different geographical regions. Gastro intestinal symptoms also vary in relation to serum creatinine and glomerular filtration rate. With increase in serum creatinine1 and decrease in GFR gastro intestinal symptoms like anorexia, 
nausea, vomiting, hiccups, epigastria pain regurgitation, dyspepsia, heart burn, Dysphagia, haematemesis, duodenal ulcer, angiodysplasia, esophagitis, gastric erosion, hiatus hernia are common manifestations.

Among upper gastrointestinal lesions caused by chronic kidney disease gastritis, esophagitis, gastric ulcer are the most prevalent lesions. Upper GI bleed is reported to cause death in 3 to $7 \%$ in CKD patients. These lesions are more common in advanced stage of CKD. The symptoms due to these lesions can markedly affect the quality of life.

Various studies have been conducted on relation between gastrointestinal lesions and CKD patients. A prevalence of $72.9 \%$ was found by serme4 et al in Burkina Faso and in Italy it was $74 \%$ accordingly to Nardone 5 et al. Upper gastro intestinal lesions in our series had predominant localization in gastric and duodenal level.Several studies have identified and recognized that early diagnosis and management of these upper gastro intestinal lesions reduce mortality and morbidity in CKD patients. Here an attempt is being made to study the upper gastro intestinal changes in chronic kidney disease and evaluate their relationship with the stage of CKD or GFR.

\section{Objectives of the Study}

1. To determine the prevalence of various upper gastro intestinal lesions with theuse of fibro optic endoscopy.

2. To evaluate the relation between the gastro intestinal lesion with the stage ofCKD or GFR.

\section{Subjects and Methods}

\section{Source of Data}

Patients presenting to outpatient and inpatient department, Department of General Medicine, Navodaya Medical College and Research center, Raichur.

Study design: Cross sectional study.

Study period: One year

\section{Sample Size}

A total of 50 subjects diagnosed to have chronic kidney disease, presented to outpatient department or were admitted to Navodaya medical college and research center, fulfilling inclusion criteria were included in this study.

\section{Inclusion criteria}

Adult Patients diagnosed to have chronic kidney disease and age more than 18 years.

\section{Exclusion criteria}

1. Patients with history of Acid Peptic Disease.

2. Patients on high dose NSAIDs for a long duration of time

3. Patients of cirrhosis of liver with esophageal varices.

4. Patients with history chronic alcoholism, chronic smoking and chronic tobacco chewing

5. Patients diagnosed with AKI

\section{Criteria for diagnosing chronic kidney disease}

1. Symptoms of uremia for 3 months or more.

2. Elevated blood urea, serum creatinine and decreased creatinine clearance

3. Ultrasound evidence of CKD a. Bilateral contracted kidney -size less than $8 \mathrm{~cm}$ in male and size less than $7 \mathrm{~cm}$ in female

b. Poor cortico medullary differentiation

c. Type 2 or 3 renal parenchyma changes Supportive laboratory evidence of CKD like anemia, low specific gravity, changes in serum electrolytes etc.

Staging of chronic kidney disease is based on Glomerular filtration rate. Cockcroft-Gault formula was used to calculate the glomerular filtration rate. Detailed clinical history and clinical examination is under taken with preference to gastro intestinal related complaints and renal diseases. The following investigations were performed.

1. Hemoglobin, total count, ESR

2. RBS

3. Blood urea, serum creatinine

4. Serum electrolytes

5. Urine analysis

6. ECG

After selecting the patients fulfilling the above criteria, they were subject to upper gastro intestinal endoscopy at our institute, using flexible fibreoptic endoscope, manufactured by Olympus Inc.

\section{Results}

A total number of 50 cases were studied over a period of one year. Various parameters such as GFR was calculated and tabulated along with findings of upper gastrointestinal endoscopy. These parameters were later analyzed using the SPSS v16.0 software at the Department of Social and Preventive Medicine, Navodaya Medical College, Raichur. There are 6 subjects in our study ranging from 19 to 30 years age group, 13 subjects ranging from 31 to 40 years, 8 subjects ranging from 41 to 50years, 12 subjects ranging from 51 to 60years, 8 subjects ranging from 61 to 70 years, 3 subjects ranging from 71 to 80years. Majority of the subjects belong to age group of 31 to 40 years $26 \%$ and least belong to 70 to 80 years age group $6 \%$.

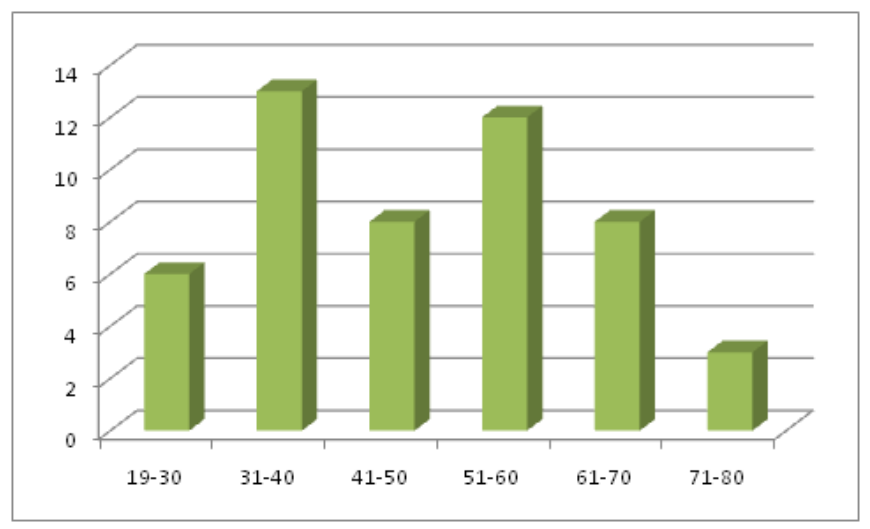

Chart1: Age wise distribution of the sample size.

Out of the 50 patients males were 28 and females were 22 . 42 patients, out of the 50, had upper gastrointestinal involvement on endoscopic examination. Remaining 8 patients had normal upper gastrointestinal mucosa.

Distribution of Patients Based On Stage

Out of 50 cases of chronic kidney disease subjects $4 \%$ 
belongs to stage II ,22\% subjects belongs to stage III, $44 \%$ subjects belongs to stage IV ,30\% subjects belongs to stage V.

Majority of the cases in our study belongs to stage IV and no patients were there in stage I.

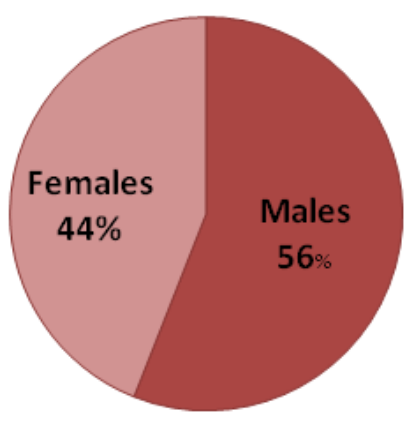

Chart2: Sex wise distribution of the sample size.

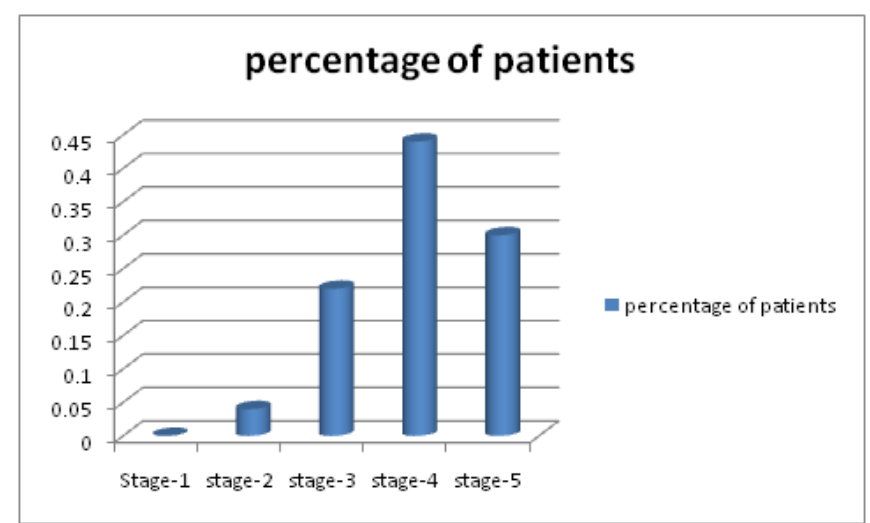

Chart3: Sex wise distribution of the sample size.

Table 1: Percentage of Various Upper Gastro Intestinal Findings in CKD Patients.

\begin{tabular}{|l|l|l|}
\hline Type of lesion & Number of patient & Percentage \\
\hline Erosive Gastritis & 13 & $26 \%$ \\
\hline GERD With or without Duodenitis & 10 & $20 \%$ \\
\hline Duodenal Ulcer & 4 & $8 \%$ \\
\hline Gastric Ulcer & 4 & $8 \%$ \\
\hline Pan Gastritis & 3 & $6 \%$ \\
\hline GERD With Gastritis & 2 & $4 \%$ \\
\hline Erosive Esophagitis & 2 & $4 \%$ \\
\hline Pale Gastric Mucosa & 2 & $4 \%$ \\
\hline Angiodysplasia Of Stomach & 1 & $2 \%$ \\
\hline Hiatus Hernia & 1 & $2 \%$ \\
\hline Normal Study & 8 & $16 \%$ \\
\hline
\end{tabular}

Out of 50 subjects, 42(84\%) had upper gastrointestinal involvement on endoscopic examination. Most common upper gastrointestinal lesion in our study is erosive gastritis $13(26 \%)$, followed by gastro esophageal reflux disease with or without Duodenitis. 10 (20\%), duodenal ulcer, gastric ulcer $4(8 \%)$ each, pan gastritis 3(6\%),GERD with gastritis, erosive esophagitis, pale gastric mucosa $2(4 \%)$ each, angiodysplasia and hiatus hernia $1(2 \%)$ each. $16 \%$ of chronic kidney disease subjects had no abnormalities in endoscopic examination.

\section{Upper Gastrointestinal Manifestations Based On CKD} Stage

Erosive gastritis $26 \%$, either antral or fundal, was the predominant lesion found on endoscopy of whom $15 \%$ of subjects belong to stage III,53.8\% of subjects belongs to stage IV ,30.7\% of subjects belong to stage V . GERD with or without Duodenitis $16 \%$ was next of whom $10 \%$ of subjects belongs to stage III, $60 \%$ of subjects belongs to stage IV, $30 \%$ of subjects belongs to stage V. Duodenal ulcers $8 \%$ of whom $50 \%$ each in stage IV and stage V. Gastric ulcers were seen in $8 \%$ of the subjects of whom $25 \%$ each in stage III and stage V, $50 \%$ of subjects were there in satge IV. Pan gastritis involving entire stomach is seen in 6\% of whom $66.6 \%$ of subjects belong to stage IV, $33.3 \%$ of subjects belongs to stage V. $4 \%$ of subjects with Esophagitis of whom $50 \%$ each in stage IV and stage V, pale gastric mucosa each contribute to $4 \%$ of subjects belongs to stage III. Angiodysplasia and hiatus hernia were seen in very few patients $2 \%$ each belongs to stage $\mathrm{V}$.

\section{Upper Gastro Intestinal Findings Based On Frequency of} involvement.

Out of 50 cases in our study $55 \%$ of subjects had lesions in stomach, $26 \%$ of subjects had lesions in duodenum, and 19 $\%$ of subjects had lesions in esophagus

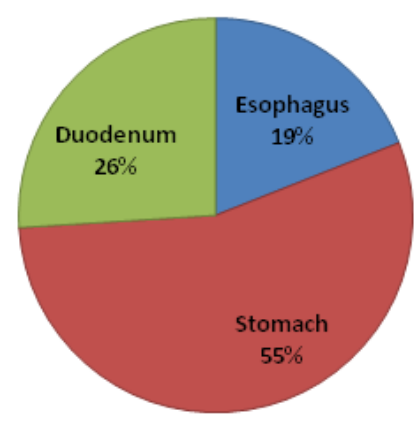

Chart 4: Percentage involvement of Upper GI in patients with CKD.

\section{Discussion}

Chronic kidney disease is associated with abnormalities of the gastrointestinal tract involving all its segments2. Endoscopy performed in patients with CKD shows wide variations in the type of lesions.

Upper gastrointestinal disorders in patients with chronic kidney disease can be considered in two aspects

1. Gastro esophageal dysmotility.

2. Mucosal lesions.

Gastro esophageal dysmotility manifests as delayed gastric emptying and gastro esophageal reflex disorder. These functional disorders are very common in adult patients. Mucosal lesions such as esophagitis, gastritis, and peptic ulcer, arise due to uremia. Several previous studies showed that the gastric and duodenal lesions to be the most frequent source of upper gastro intestinal hemorrhage.

Our study includes 50 study subjects who were diagnosed to have chronic kidney disease and fulfilled inclusion criteria. 
Various parameters assessed in this study were: upper gastrointestinal endoscopic findings, blood urea, serum creatinine, serum electrolytes, urine examination, ultrasonography of the abdomen and pelvis.

Our study highlights the high prevalence of upper gastrointestinal endoscopic lesions in patients with chronic kidney disease [84\%]. Similar study conducted by other workers in chronic kidney disease patients also shows high prevalence of upper gastrointestinal endoscopic lesions. A study done by Mohit Goyal1 et al in 2014 observed that $86 \%$ subjects have upper gastrointestinal lesions. A similar study done by Sreelatha70 et al in in 2015 has prevalence of $68 \%$. A study done by Khedmat71 in 2007 has prevalence of $79 \%$ subjects with upper gastrointestinal lesion. A similar study done by Nardone5 et al in 2005 has prevalence of $90 \%$. A study done by Al Mueilo has prevalence of $90.7 \%$. A similar study done by Agarwal73 observed

95.7\% prevalence. A similar study done by Varma74 et al has prevalence of $72 \%$ subjects with upper gastrointestinal manifestations.. The age of patients, included in our study; ranged from 19 to 80 years, of which majority of the patients belonged to younger age groups. In our study most of the patients ranging from 31 to 40 years. Among them, most of the subjects belong to stage IV. A similar study done by Sreelatha70 et al, showed that the age of subjects ranged from 14 to 80 years, with majority of the subjects belonging to the age group 21 to 40 years. A similar study done by Varma73 et al, had subjects who aged in between 17 to 70 years. Of the 50 patients in our study, $84 \%$ had upper gastrointestinal involvement on endoscopic examination. Remaining $16 \%$ had a normal endoscopic study. Erosive gastritis $26 \%$, either antral or fundal, was the predominant lesion found on endoscopy. GERD with or without duodenitis (16\%) was next. Duodenal ulcers and gastric ulcers were seen in $8 \%$ of the subjects. Pan gastritis involving entire stomach is seen in 6\%. Esophagitis, pale gastric mucosa each contribute to $4 \%$. Angiodysplasia and hiatus hernia were seen in very few patients ( $2 \%$ each). Upper gastrointestinal lesions in our study had a predominant localization to the gastric and duodenal level. In a study conducted by Varma74 et al gastritis was the major lesion $27 \%$; otherlesions seen were duodenitis $14 \%$, gastro duodenitis $20 \%$ and peptic ulcer $6.5 \%$. In astudy conducted by Sreelatha70 et al, erosive gastritis was the major lesion $16 \%$. Stomach was involved in $48 \%$, followed by esophagus (29\%) and duodenum (23\%).In the study done by Esfahani75 gastritis was predominant $(60.8 \%)$, followed by

duodenitis at $13 \%$ and gsatoduodenitis at $7.2 \%$. In a study conducted by Agarwal73 etal uremic gastropathy was found in $91.4 \%$, esophageal involvement was $63 \%$. InMouhamad eta al76 gastritis at $49 \%$ was the most common lesion, hiatus hernia $20 \%$, peptic esophagitis $16 \%$, duodenalbulbitis $14 \%$ were also reported. In Burkinia Fasostudy gastric lesions were most common with $68.7 \%$, followed by duodenal $32 \%$. In astudy conducted by Nardone 5 et al $56 \%$ of patients has gastric lesions, $18 \%$ of thesubjects has esophagitis and $36 \%$ had duodenitis. In a study conducted by MohitGoyal1 gastritis is most frequent lesion in patients with CKD (68\%), followed byesophagitis $42 \%$ and duodenitis $8 \%$. In a study done by $\mathrm{Al}$ Mueilo72 57\% of thesubjects had gastritis, $9.3 \%$ had duodenitis. In a study conducted by Margolis et al77duodenitis is most frequent lesion at $60 \%$, followed by gastric $22 \%$. Erosive gastritis $(32 \%)$ was the most common gastrointestinal lesion in a study done by Nand 2 et al.Elevated gastrin levels, Helicobacter Pylori infection, toxic effects of urea and othertoxic molecules on gastric mucosa are thought to be responsible for erosive gastritis Majority of the subjects in our study 22 out of 50 belong to stage IV $44 \%$ ofwhich $95 \%$ have upper gastrointestinal involvement; followed by stage V 30\% Ofwhich 100\% have upper gastrointestinal involvement, followed by stage III $22 \%$ ofwhich $54.5 \%$ have upper gastrointestinal involvement . $4 \%$ of subjects belong to stageII , the upper gastrointestinal endoscopy examination reveals no abnormality. Thestudy does not include subject belong to stage I.A study done by sreelatha70 et al has majority of the patients 30 out of 50 , belong to stage $\mathrm{V}$ chronic kidney disease of which 21 subjects $(70 \%)$ showed uppergastrointestinal involvement.14 subjects belong to stage IV of whom 8 subjects $(57 \%)$ have upper gastrointestinal manifestations . 6 subjects belong to stage III of which 5subjects $(83.3 \%)$ have upper gastrointestinal involvement A similar study done by Mohit Goyall et al observed that endoscopic lesions were common in Stage $\mathrm{V}$ than in stage IV of chronic kidney disease. $88 \%$ of subjects having gastritis were in stage $\mathrm{V}$, whereas only $12 \%$ of the subjects with gastritis were in stage IV. Among subjects with stage IV, chronic kidney disease; $45 \%$ had no gastrointestinal lesions whereas only $3 \%$ of the patients in Stage V of ChronicKidney Disease had no endoscopic evidence of gastrointestinal lesions. Among 50 patients 24 (48\%) were on conservative treatment and 26 (52\%) were undergoing haemodialysis. Out of 26 patients on Hemodialysis $25(96.1 \%)$ had upper gastrointestinal lesion. Out of 24 patients on conservative treatment $17(70.8 \%)$ had upper gastrointestinal lesions. A similar study done by Sreelatha70 et al of 50 subjects $26(52 \%)$ were undergoing haemodialysis, $18(36 \%)$ subjects underwent conservative management and 6 (12\%) subjects underwent CAPD. Out of 26 HDsubjects $18(69.2 \%)$ had upper gastrointestinal involvement and 18 patients who were put on conservative management, $11(61.1 \%)$ patients had positive endoscopic findings.

\section{Conclusion}

1. Majority of the patients with chronic kidney disease have upper gastrointestinal involvement on endoscopic evaluation.

2. Erosive gastritis is the most common upper gastrointestinal manifestation in our study.

3. Upper gastrointestinal manifestations are predominant in stage $\mathrm{V}$.

4. Upper gastrointestinal findings are frequently observed in chronic kidney disease patients on dialysis.

5. Early diagnosis and management can reduce mortality and morbidity and prevent fatal complication like massive upper gastrointestinal bleed.

\section{References}

1. Goyal, M., Charan, S., Singh, S., Chawla, S. P. S., Garg, R., \&Kaur, 
S. (2014). Study of upper gastrointestinal changes in chronic kidney disease. International Journal of Bioassays, 3(11), 3526-3531.

2. Nand, N., Malhotra, P., \&Bala, R. (2014). Evaluation of upper gastrointestinal symptoms and effect of different modalities of treatment in patients of chronic kidney disease. JIACM,15(3-4),1827.

3. Krishnan, A., Sigamani, R., \&Venkataraman, J. (2011). Gastrointestinalevaluation in chronic kidney diseases. J Nephrol Therapeutic, 1(3), 110. 17

4. Serme AK, Lengani A, Ilboudo PD, Sawadogo N, Sombie R. Les lesions endoscopiques digestives hautesdansl'insuffisancerénalechroniquesévère en Afrique Noire. Médecined'Afrique noire. 2003;50(1):31-6.

5. Nardone G, Rocco A, Fiorillo M, Del Pezzo M, Autiero G, Cuomo R, Sarnelli G, Lambiase A, Budillon G, Cianciaruso B. Gastroduodenal lesions and Helicobacter pylori infection in dyspeptic patients with and without chronic renal failure. Helicobacter. $2005 \mathrm{Feb}$ 1;10(1):538 .

6. Schneider S, Malecki AK, Boenisch O, Schönfeld R, Kielstein JT. Cognitiv function at $2443 \mu \mathrm{mol} / \mathrm{l}$ creatinine. BMC nephrology. 2012 Aug 15;13(1):86.

7. Eknoyan G. The Early Modern Kidney-Nephrology in and about the Nineteenth Century (Part 2). InSeminars in dialysis 2014 Sep 1 (Vol. 27, No. 5, pp. 494-503)

8. George CR. William Charles Wells (1757-1815) - a nephrologist of the Scottish enlightenment. Nephrology Dialysis Transplantation. 1996 Dec 1;11(12):2513-7.

9. Wöhler F. Friedrich Wöhler.Bright R. History of nephrology: the middle period. History. 2012

10. Wills MR. Biochemical consequences of chronic renal failure: a review. Journal of pathology. 1968 Sep;21(5):541

11. Witting C. The Terminology of Glomerulonephritis A Review. InGlomerulonephritis 1976 (pp. 45-60).

12. Springer, Berlin, Heidelberg.Steensma DP, Kyle RA. A history of the kidney in plasma cell disorders.InThe Kidney in Plasma Cell Dyscrasias 2007 (Vol. 153, pp. 5-24). Karger Publishers.

13. Cameron JS. A history of urine microscopy. Clinical Chemistry andLaboratory Medicine (CCLM). 2015 Nov 1;53(s2):s1453-64.

14. Doherty CC. Peptic ulcer and chronic renal failure. The Ulster medicaljournal. 1979;48(2):145.

15. Moynihan BG. Uremic Ulcer of the Duodenum. Duodenal Ulcer. WBSaunders Co. 1910:44.

16. Shepherd AM, Stewart WK, Wormsley KG. Peptic ulceration in chronic renalfailure. The Lancet. 1973 Jun 16;301(7816):1357-9.

17. Moore TC, Hume DM. The period and nature of hazard in clinical renaltransplantation. I. The hazard to patient survival. Annals of Surgery. 1969Jul;170(1):1.

18. Tisher CC, Kristen M. Anatomy of the Kidney In:BrennerBM,edition.BrennerandRectors's The Kidney, vol 1 6th edn, Philadelphia; WB Saunders comp:2000 p 3-67.

19. Skorecki, K., Chertow, G. M., Marsden, P. A., Taal, M. W., Alan, S. L., \&Luyckx, V. (2015)

20. Brenner and Rector's The Kidney E-Book. Elsevier Health SciencesSchieppati A, Remuzzi G. Chronic renal diseases as a public health problem: epidemiology, social, and economic implications. Kidney International. 2005Sep 30;68:S7-10

21. Jha V, Garcia-Garcia G, Iseki K, Li Z, Naicker S, Plattner B, Saran R, WangAY, Yang CW. Chronic kidney disease: global dimension and perspectives.The Lancet. 2013 Jul 26;382(9888):260-72.

22. Rajapurkar MM, John GT, Kirpalani AL, Abraham G, Agarwal SK, AlmeidaAF, Gang S, Gupta A, Modi G, Pahari D, Pisharody R. What do weknowabout chronic kidney disease in India: first report of the Indian CKD registry.BMC nephrology. 2012 Mar 6;13(1):10.

23. Zhang L, Wang F, Wang L, Wang W, Liu B, Liu J, Chen M, He Q, Liao Y,Yu X, Chen N. Prevalence of chronic kidney disease in China: a crosssectionalsurvey. The Lancet. 2012 Mar 9;379(9818):815-22.

24. Arogundade FA, Barsoum RS. CKD prevention in Sub-Saharan Africa: a callfor governmental, nongovernmental, and community support. AmericanJournal of Kidney Diseases. 2008 Mar 31;51(3):515-23

25. Feehally J. Ethnicity and renal disease. Kidney international. 2005 Jul1;68(1):414-24.

26. Levey AS, Atkins R, Coresh J, Cohen EP, Collins AJ, Eckardt KU, NahasME, Jaber BL, Jadoul M, Levin A, Powe NR. Chronic kidney disease as aglobal public health problem: approaches and initiatives-a position statementfrom Kidney Disease Improving Global Outcomes.
Kidney international. 2007Aug 1;72(3):247-59

27. Inker LA, Astor BC, Fox CH, Isakova T, Lash JP, Peralta CA, Tamura MK, Feldman HI. KDOQI US commentary on the 2012 KDIGO clinical practiceguideline for the evaluation and management of CKD. American Journal ofKidney Diseases. 2014 May 31:63(5):713-35

28. Kasper DL, Braunwald E, Fauci AS, Hauser SL, Longo DL, Jameson JL. Harrisons manual of medicine. McGraw-Hill Medical Publishing Division;2016 May

29. Levey AS, Eckardt KU, Tsukamoto Y, Levin A, Coresh J, Rossert J, ZeeuwDD, Hostetter TH, Lameire N, Eknoyan G. Definition and classification of chronic kidney disease: a position statement from Kidney Disease: Improving Global Outcomes (KDIGO). Kidney international. 2005 Jun 30;67(6):2089-100.

30. El NahasAM, Bello AK. Chronic kidney disease: the global challenge. The Lancet. 2005 Jan 22;365(9456):331-40

31. Bergman S, Key BO, Kirk KA, Warnock DG, Rostand SG. Kidney disease inthe first-degree relatives of African-Americans with hypertensive end-stagerenal disease. American journal of kidney diseases. 1996 Mar 1;27(3):341-6

32. Buck K, Feehally J. Diabetes and renal failure in Indo-Asians in the UK - a paradigm for the study of disease susceptibility. Nephrology, dialysis, transplantation: official publication of the European Dialysis and Transplant Association-European Renal Association. 1997 Aug 1;12(8):1555-7.

33. Brenner BM, Chertow GM. Congenital oligonephropathy and the etiology ofadult hypertension and progressive renal injury. American journal of kidneydiseases. $1994 \mathrm{Feb}$ 1;23(2):171-5.1)

34. Kalantar-Zadeh K, Ikizler TA, Block G, Avram MM, KoppleJD.Malnutrition-inflammation complex syndrome in dialysis patients: causes andconsequences. American Journal of Kidney Diseases. 2003 Nov 30;42(5):864-81.

35. Klag MJ, Whelton PK, Randall BL, Neaton JD, Brancati FL, Stamler J. Endstagerenal disease in African-American and white men: 16-year MRFITfindings. Jama. 1997 Apr 23;277(16):1293-8.

36. Iseki K. The Okinawa screening program. Journal of the American Society ofNephrology. 2003 Jul 1;14(suppl 2):S127-30.

37. Sarnak MJ, Levey AS, Schoolwerth AC, Coresh J, Culleton B, Hamm LL,McCullough PA, Kasiske BL, Kelepouris E, Klag MJ, Parfrey P. Kidneydisease as a risk factor for development of cardiovascular disease. Circulation.2003 Oct 28;108(17):2154-69

38. Jungers $\mathrm{P}$, Chauveau P, Descamps-Latscha B, Labrunie M, Giraud E, ManNK, Grünfeld JP, Jacobs C. Age and gender-related incidence of chronic renalfailure in a French urban area: a prospective epidemiologic study. NephrologyDialysis Transplantation. 1996 Aug $1 ; 11(8): 1542-6$

39. Hannedouche T, Chauveau P, Kalou F, Albouze G, Lacour B, JungersP.Factors affecting progression in advanced chronic renal failure. Clinicalnephrology. 1993 Jun;39(6):312-20.

40. Hsu CY, Lin F, Vittinghoff E, Shlipak MG. Racial differences in theprogression from chronic renal insufficiency to end-stage renal disease in theUnited States. Journal of the American Society of Nephrology. 2003 Nov1;14(11):2902-7.

41. Klahr S, Levey AS, Beck GJ, Caggiula AW, Hunsicker L, Kusek JW, StrikerG. The effects of dietary protein restriction and blood-pressure control on theprogression of chronic renal disease. New England Journal of Medicine. 1994Mar 31;330(13):877-84.

42. Jafar TH, Stark PC, Schmid CH, Landa M, Maschio G, de Jong PE, de Zeeuw D, Shahinfar S, Toto R, Levey AS. Progression of chronic kidney disease: the role of blood pressure control, proteinuria, and angiotensin-converting enzyme inhibition: a patient-level metaanalysis. Annals of internal medicine. 2003 Aug 19;139(4):244-52.

43. Iseki K, Kinjo K, Iseki C, Takishita S. Relationship between predicted creatinine clearance and proteinuria and the risk of developing ESRD in Okinawa, Japan. American Journal of Kidney Diseases. 2004 Nov30;44(5):806-14.

44. Remuzzi G, Bertani T. Pathophysiology of progressive nephropathies. NewEngland Journal of Medicine. 1998 Nov 12;339(20):1448-56

45. Gowda MA. Evaluation of Thyroid Function Status in Patients with ChronicKidney.

46. Kim, M. J., Kwon, K. H., \& Lee, S. W. (1998). Gastroesophagealrefluxdisease in CAPD patients. Advances in Peritoneal Dialysis, 14, 98-101.

47. Kang, J. Y., Ho, K. Y., Yeoh, K. G., Guan, R., Wee, A., Lee, E., ...\& Tan, C.C. (1999). Peptic ulcer and gastritis in uraemia, with particular reference to theeffect of Helicobacter pylori infection. Journal of 
gastroenterology andhepatology, 14(8), 771-778.

48. De Schoenmakere, G., Vanholder, R., Rottey, S., Duym, P., \&Lameire, N.(2001). Relationship between gastric emptying and clinical and biochemicalfactors in chronic haemodialysis patients. Nephrology DialysisTransplantation, 16(9), 1850-1855

49. Strid, H., Simren, M., Stotzer, P. O., Abrahamsson, H., \&Björnsson, E. S.(2004). Delay in gastric emptying in patients with chronic renal failure.Scandinavian journal of gastroenterology, 39(6), 516-520

50. Silang, R., Regalado, M., Cheng, T. H., \& Wesson, D. E. (2001). Prokineticagents increase plasma albumin in hypoalbuminemic chronic dialysis patientswith delayed gastric emptying. American journal of kidney diseases, 37(2),287-293

51. 52) Scheff, R. T., Zuckerman, G., Harter, H. E. R. S. C. H. E. L., Delmez, J. A. M.E. S., \& Koehler, R. (1980). Diverticular disease in patients with chronic renalfailure due to polycystic kidney disease. Ann Intern Med, 92(2 Pt 1), 202-204.

52. Adams, P. L., Rutsky, E. A., Rostand, S. G., \& Han, S. Y. (1982). Lowergastrointestinal tract dysfunction in patients receiving longterm hemodialysis. Archives of internal medicine, 142(2), 303-306.

53. Zeier, M., Wiesel, M., Rambausek, M., \& Ritz, E. (1995). Nonocclusivemesenteric infarction in dialysis patients: the importance of prevention andearly intervention.

54. Tsai, C. J., \& Hwang, J. C. (1996). Investigation of upper gastrointestinalhemorrhage in chronic renal failure. Journal of clinical gastroenterology,22(1), 2-5.

55. Yorioka, N., Hamaguchi, N., Taniguchi, Y., Asakimori, Y., Nishiki, T., Oda,H., \&Yamakido, M. (1996). Gastric antral vascular ectasia in a patient onhemodialysis improved with CAPD. Peritoneal dialysis international, 16(2), 177

56. Cunney, R. J., Magee, C., McNamara, E., Smyth, E. G., \&Walshe, J. (1998).Clostridium difficile colitis associated with chronic renal failure. Nephrology,dialysis, transplantation: official publication of the European Dialysis andTransplant Association-European Renal Association, 13(11), 2842-2846.

57. Lankisch, P. G., Weber-Dany, B., Maisonneuve, P., \&Lowenfels, A. B.(2007). Frequency and severity of acute pancreatitis in chronic dialysispatients. Nephrology Dialysis Transplantation, 23(4), 14011405.

58. Morris-Stiff, G., Coles, G., Moore, R., Jurewicz, A., \& Lord, R. (1997).Abdominal wall hernia in autosomal dominant polycystic kidney disease.British journal of surgery, 84(5), 615-617.

59. Woodrow, G., Innes, A., Boyd, S. M., \& Burden, R. P. (1993). A case of IgAnephropathy with coeliac disease responding to a gluten-free diet. NephrologyDialysis Transplantation, 8(12), 1382-1383.

60. Strid, H., Simrén, M., \&Björnsson, E. S. (2003). Overuse of acid suppressantdrugs in patients with chronic renal failure. Nephrology DialysisTransplantation, 18(3), 570-575.

61. Rathert P, Lutzeyer W, Goddwin WE. Philipp Bozzini (1773-1809) and thelichtleiter. Urology. 1974 Jan 1;3(1):113-8.

62. Desormeaux AJ. The Endoscope, and Its Application to the Diagnosis andTreatment of Affections of the Genito-urinary Passages: Lessons
Given atNecker Hospital. Robert Fergus' Sons, printers; 1867.

63. Eslick GD. Esophageal cancer: a historical perspective GastroenterologyClinics of North America. 2009 Mar 31;38(1):1-5.

64. Schindler R, Eusterman GB. GASTROSCOPY: THE ENDOSCOPIC STUDYOF GASTRIC PATHOLOGY. Annals of Surgery. 1937 Nov 1;106(5):958

65. Hirschowitz BI, Balint JA, Fulton WF. Gastroduodenal endoscopy with thefiberscope - an analysis of 500 examinations. Surgical Clinics of NorthAmerica. 1962 Oct 31;42(5):1081-90.

66. Fanti L, Agostoni M, Gemma M, Radaelli F, Conigliaro R, Beretta L, Rossi G,Guslandi M, Testoni PA. Sedation and monitoring for gastrointestinalendoscopy: A nationwide web survey in Italy. Digestive and Liver Disease.2011 Sep 30;43(9):726-30.

67. Waring JP, Baron TH, Hirota WK, Goldstein JL, Jacobson BC Leighton JA,Mallery JS, Faigel DO. Guidelines for conscious sedation and monitoringduring gastrointestinal endoscopy. Gastrointestinal endoscopy. 2003 Sep30;58(3):317-22.

68. Cisse, M. M., Fary, K. E. H., Daouda, D., Mahamat, A. G., \&Nzambaza, J. D.D. (2015). Upper Digestive Endoscopic Lesions in Chronic Kidney Disease(CKD): Experience of a Senegalese Center; About 50 Cases. J Nephrol Ther,5(202), 2161-0959.

69. Sreelatha, M., Kumar, V. S., Shekar, G. C., \&Shekar, V. C. UpperGastrointestinal Manifestations in Chronic Renal Failure Through UpperGastrointestinal Endoscopy

70. Khedmat H, Ahmadzad-Asl M, Amini M, Lessan-Pezeshki M EinollahiB,Pourfarziani V, Naseri MH, Davoudi F. Gastro-duodenal lesions andHelicobacter pylori infection in uremic patients and renal transplant recipients.InTransplantation proceedings 2007 May 31 (Vol. 39, No. 4, pp. 1003-1007).Elsevier.

71. Al-Mueilo SH. Gastroduodenal lesions and Helicobacter pylori infection inhemodialysis patients. Saudi medical journal. 2004;25(8):1010-4.

72. Agarwal SK, Srivastava RK. Chronic kidney disease in India: challenges andsolutions. Nephron clinical practice. 2009;111(3):c197203.

73. Varrma PP, Pruthi HS, Thakur SK, Prasher PK, Singh B. Uppergastrointestinal bleeding in chronic renal failure. Indian $\mathrm{J}$ Nephrol 1996;6:150-2

74. Esfahani, S. T., Madani, A., Ataei, N., Nadjafi, M., Mohseni, P., Allahverdi,B., \&Haddadi, M. (2009). Upper gastrointestinal disorders in children withend-stage renal disease. ActaMedicaIranica, 47(1), 46-50.

75. Moustafa FE, Khalil A, Wahab MA, Sobh MA. Helicobacter pylori anduremic gastritis: a histopathologic study and a correlation with endoscopic andbacteriologic findings. American journal of nephrology. 1997;17(2):165-71.

76. Margolis DM, Saylor JL, Geisse G, DeSchryver-Kecskemeti K, Harter HR,Zuckerman GR. Upper gastrointestinal disease in chronic renal failure: aprospective evaluation. Archives of internal medicine. 1978 Aug1;138(8):1214-7.

Copyright: () the author(s), 2019. It is an open-access article distributed under the terms of the Creative Commons Attribution License (CC BY 4.0), which permits authors to retain ownership of the copyright for their content, and allow anyone to download, reuse, reprint, modify, distribute and/or copy the content as long as the original authors and source are cited.

How to cite this article: Shivraj, Venugopal K. Gastrointestinal Manifestations in Patients with Chronic Kidney Disease. Acad. J. Med.2019;2(2):54-59.

DOI: dx.doi.org/10.21276/ajm.2019.2.2.15 